\title{
Applied Assessment Process for Priority of Bridge Maintenance in Sudan
}

\author{
Eltayeb Hassan Onsa ${ }^{1}$, Salah Eldin Yousif Hassan ${ }^{2}$, and Ahmed Gasim Mahmoud ${ }^{3}$
}

\begin{abstract}
The decision making for performing bridges maintenance might be difficult in presence of various affecting criteria. This paper attempts to apply the Fuzzy Analytical Hierarchy Process in the decision making for bridge maintenance on way to help the local authorities to decide on priority of maintenance between two bridges, in Khartoum State (Sudan). The two bridges are located along the same corridor and have the same level of distress. The opinion of four experts is pair-wise analyzed for the selection of priority of maintenance. A questionnaire is designed and analyzed using Nang's approach. Weights, from group of evaluations, are analyzed using excel spread sheets developed by the Authors. The outcome of the analysis revealed a logical procedure which successfully utilizes the use of FAHP to promote the decision processes regarding priority of bridges maintenance.

After accepting the outcome results of this study, the local authority commenced maintenance of the first bridge which was successfully completed few months ago. Lessons learned from applying these results on real project are presented.
\end{abstract}

Keywords - Bridge maintenance, assessment process, Fuzzy Analytical Hierarchy Process.

\section{INTRODUCTION}

$\mathrm{T}$ HE Ministry of Infrastructures and Transportation (MIT) of Khartoum State (KS) - Sudan, has performed investigations and assessment of two main bridges, namely: the Blue Nile Bridge (BNB) [1] and Burri Bridge (BB) [2]. The results indicated that the level of distress is approximately the same in the two bridges and both bridges are in need for urgent major maintenance. The two bridges, according to the city traffic master plan, are linking Khartoum North with Khartoum across the Blue Nile; each of the two bridges plays special effective role in KS transportation services, see Fig. 1 To allow establishing realistic and effective criteria, the extent of influencing function of the bridges connecting Khartoum North with Khartoum are summarized in Table 1. Maintenance information of the BNB and $\mathrm{BB}$ is presented Table 2.

Based on the above data it was concluded that closing either of the two subject bridges for priority of maintenance may result in negative impacts to the traffic system in the area and may seriously affect citizens' life. This critical the situation let

Eltayeb Hassan Onsa ${ }^{1}$ and Ahmed Gasim Mahmoud ${ }^{3}$, are Associate Profs. at the Dept. of Civil Engineering, Faculty of Engineering Sciences, Omdurman Islamic University, (Sudan): e-mail: eonsah@ gmail.com

Salah Eldin Yousif Hassan ${ }^{2}$ is the Head of Bridge Maintenance Dept. at the Roads and Bridges Corporation in the Ministry of Infrastructure and Transportation - Khartoum State (Sudan). the MIT insists to use precise and measurable method to reach effective decision in: "which bridge from the two bridges is to be set for maintenance at present time; whereas maintenance of the other bridge to done later".

Bearing in mind that: simultaneous maintenance of the two bridges is prohibited in view of tremendous and hazardous traffic problems expected to occur.

\section{BRIEF DATA OF GREATER KHARTOUM}

Greater Khartoum $\left(32^{\circ} 32^{\prime} 53^{\prime \prime}\right.$ E, $\left.15^{\circ} 36^{\prime} 58^{\prime \prime} \mathrm{N}\right)$ is the capital of Sudan and is the main city in Khartoum State. The city is divided into three districts: 1 . Khartoum; which is the main political capital of Sudan, characterized by accommodating most of official authorities and administrations, diplomatic representative, public services, commercial banks, and main commercial activities; 2 . Omdurman; is the city of heritages with the higher number of population; 3. Khartoum North; is characterized by its industrial and agricultural activities, and is a residential city as well, see Fig. 1.

The three districts are isolated from each other by three rivers: the Blue Nile between Khartoum and Khartoum North, the White Nile between Khartoum and Omdurman. Both Blue Nile and White Nile join at Khartoum forming the start of the River Nile which flows between Khartoum North and Omdurman towards north direction. There exist seven bridges as corridors linking between the three districts. Four bridges are linking Khartoum to Khartoum North across the Blue Nile through deferent routs within the main traffic network. The traffic data and beneficial aspects from the four bridges are shown in Table 1. The degree of the beneficial measures is a matter of uncertainty, therefore deciding on which bridge should be closed for maintenance, considering the recent complicated conditions, is a subject of logical evaluation that can be assessed by intensive judgment and analysis.

\section{The APPLIED Method}

The FAHP is defined as mapping of human being opinion for vagueness and uncertainty into exact numerals. The FAHP proposed by Nang [3] is applied here for bridge maintenance management to assist in avoiding decision that exerts negative impacts in the surroundings. Case study for selecting one from two bridges for priority of maintenance is presented hereinafter. 


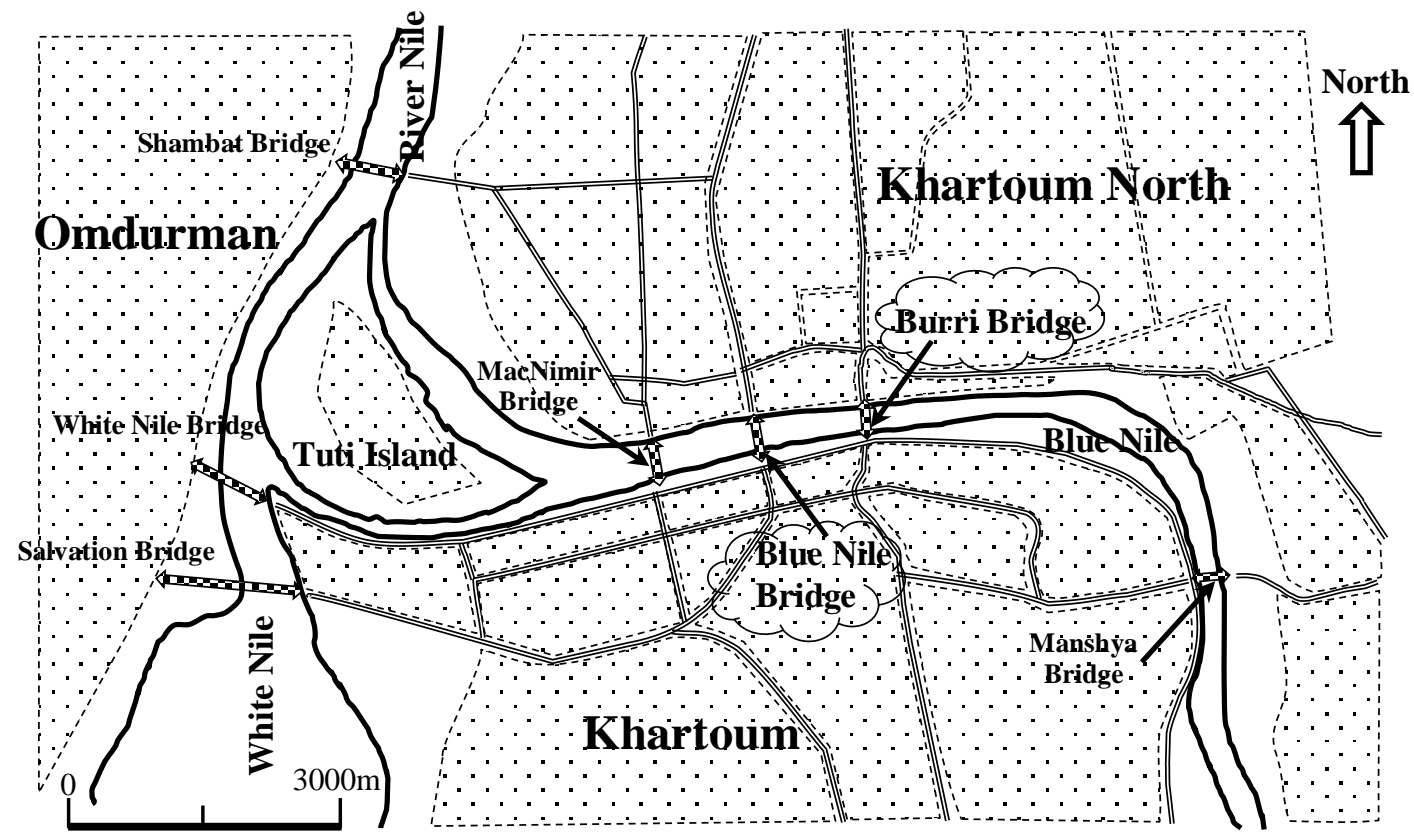

Fig. 1 Location Map

TABLE 1

BASIC DATA OF THE FOUR BRIDGES LINKING KHARTOUM WITH KHARTOUM NORTH [4]

\begin{tabular}{|c|c|c|c|c|}
\hline No. & Bridge name & Type of superstructure & $\begin{array}{l}\text { Recent } \\
\text { AADT* } \\
\text { (PCUs) }\end{array}$ & Description of potential aspects \\
\hline 1 & $\begin{array}{l}\text { Mac Nimir } \\
\text { Bridge }\end{array}$ & $\begin{array}{l}\text { Composite, continuous } \\
\text { twin steel box girders }\end{array}$ & 53,000 & $\begin{array}{l}\text { Links Khartoum with Khartoum North; links centers of the two } \\
\text { towns. }\end{array}$ \\
\hline 2 & $\begin{array}{l}\text { Blue Nile } \\
\text { Bridge }\end{array}$ & Steel truss & 40,000 & $\begin{array}{l}\text { Links Khartoum with Khartoum North through one route } \\
\text { extending to the extreme northern extensions where production } \\
\text { areas of vegetables and fruits; villagers and local national } \\
\text { markets. Main duty free zone and other industrial area; schools } \\
\text { and universities. Main railway station. Khartoum University. }\end{array}$ \\
\hline 3 & Burri Bridge & $\begin{array}{l}\text { Prestressed concrete } \\
\text { cantilever box girder }\end{array}$ & 72,000 & $\begin{array}{l}\text { Links Khartoum to the main industrial area at Khartoum North } \\
\text { and the traffic extends to the east to link vast residential areas. } \\
\text { Where the main natural building materials transported from the } \\
\text { resources to Khartoum vast districts. } \\
\text { The route passes vast residential area to Khartoum industrial } \\
\text { area, greater Khartoum marketing zones, to the interstate } \\
\text { highways. }\end{array}$ \\
\hline 4 & $\begin{array}{l}\text { Manshya } \\
\text { Bridge }\end{array}$ & $\begin{array}{l}\text { Twin prestressed } \\
\text { concrete box girders }\end{array}$ & 60,000 & $\begin{array}{l}\text { Links the routes from eastern Khartoum to East Nile Locality at } \\
\text { Khartoum North. Note that: it is difficult to detour traffic from } \\
\text { other nearby bridges, since this bridges is almost congested by } \\
\text { its own traffic and long detouring routs are expected. }\end{array}$ \\
\hline
\end{tabular}

*Annual Average Daily Traffic in Passenger Car Units.

Closing either of the two subject bridges, completely or partially, for maintenance is expected to result in hazardous impacts which differ in magnitude from one decision to another considering the current political, economic and social situation in Khartoum State. The later three aspects are represented in this paper by main criteria and subcriteria as shown in Table 3.

Two expert engineers, specialized in bridge construction and maintenance, and two town planners were asked to identify possible factors that can affect the final decision through several survey questionnaires. The criteria used in the hierarchy were obtained and checked through the discussion process using Delphi approach [5]. Table 3 illustrates the judgments adopted in the process.

\section{A. Construction of the Hierarchy}

Fuzzy AHP decision problem usually consists of the following components [4]:

1. Alternatives, $M_{i}(i=1,2 \ldots m), m=$ number of alternatives

2. Set of evaluation criterion, $C_{j}(j=1,2 \ldots n), n=$ number of criteria 
TABLE II

MAINTENANCE DATA OF THE BNB AND BB

\begin{tabular}{|c|c|c|c|c|c|}
\hline $\begin{array}{l}\text { Bridge } \\
\text { name }\end{array}$ & Bridge main features & $\begin{array}{l}\text { Allowed } \\
\text { traffic }\end{array}$ & Required maintenance & $\begin{array}{c}\text { Cost } \\
\text { of maintenance } \\
\text { (US } \\
\text { Dollars) } \\
\end{array}$ & $\begin{array}{c}\text { Expected } \\
\text { Duration of } \\
\text { maintenance }\end{array}$ \\
\hline $\begin{array}{l}\text { Blue Nile } \\
\text { Bridge } \\
\text { (BNB) }\end{array}$ & $\begin{array}{l}\text { Constructed in 1908. Consists } \\
\text { of } 7 \text { steel truss spans, } 2 \text { plate } \\
\text { girder approach spans, and one } \\
\text { lifting span to facilitate } \\
\text { navigation. All spans are } \\
\text { simply supported. } \\
\text { Total length of the bridge = } \\
560 \mathrm{~m} \text {. }\end{array}$ & $\begin{array}{l}\text { Trains, } \\
\text { minibuses } \\
\text { and } \\
\text { private } \\
\text { cars }\end{array}$ & $\begin{array}{l}\text { Strengthening cross girders and stringers. } \\
\text { Strengthening approach plate girder spans. } \\
\text { Remove paint from all steel members and apply } \\
\text { new paining. Strengthening the cylindrical piers } \\
\text { and piers bracings. Widening the walkway to } \\
\text { accommodate traffic. Removing and replacing the } \\
\text { bridge paving concrete and asphalt after checking } \\
\text { steel troughing. Changing the expansion joints. } \\
\text { Repairing and install new lighting system and } \\
\text { traffic furniture. }\end{array}$ & $15,330,000$ & 24 Months \\
\hline $\begin{array}{l}\text { Burri } \\
\text { Bridge } \\
\text { (BB) }\end{array}$ & $\begin{array}{l}\text { Constructed in 1973. Made of } \\
\text { prestressed concrete box } \\
\text { girders. The main bridge is } \\
516 \mathrm{~m} \text { long consists of } 6 \\
\text { balance cantilever spans. Each } \\
\text { cantilever length is } 43 \mathrm{~m} \text {. }\end{array}$ & $\begin{array}{l}\text { All, } \\
\text { except } \\
\text { train }\end{array}$ & $\begin{array}{l}\text { Repair and seal cracks in the box girders and } \\
\text { diaphragms. Strengthen the } 12 \text { cantilever box } \\
\text { girders in six spans by external additional } \\
\text { Prestressing. Remove and replace sidewalk. } \\
\text { Replace expansion joints. Replace paving. Erect } \\
\text { new lighting system. Correct camber of the bridge } \\
\text { deck. }\end{array}$ & $9,850,000$ & 28 Months \\
\hline
\end{tabular}

TABLE III

EFFeCtive Criteria For Selecting One From Two Bridges For Priority Of MaintenanCe

\begin{tabular}{|c|c|c|c|c|}
\hline No. & Criterion & Notation & Sub-criteria & Reason for impact \\
\hline 1 & Cost & $C_{l}$ & $\begin{array}{l}\text { Maintenance cost } \\
\text { Detouring cost }\end{array}$ & $\begin{array}{l}\text { High maintenance cost and expensive traffic detouring processes } \\
\text { will affect the treasury }\end{array}$ \\
\hline 2 & Time duration & $C_{2}$ & $\begin{array}{l}\text { Environmental impact } \\
\text { Political impact }\end{array}$ & $\begin{array}{l}\text { Posting a bridge for long period will exert district pollution. By } \\
\text { closing the roads and intersection; politicians may respond to } \\
\text { public claims and may enforce stopping maintenance processes. }\end{array}$ \\
\hline 3 & Traffic impact & $C_{3}$ & $\begin{array}{l}\text { Site traffic } \\
\text { City traffic }\end{array}$ & $\begin{array}{l}\text { The adjacent traffic may cause maintenance ineffectiveness and } \\
\text { the site workers might be in unsafe situation. City traffic network } \\
\text { may collapse. }\end{array}$ \\
\hline 4 & $\begin{array}{l}\text { Security and } \\
\text { emergency }\end{array}$ & $C_{4}$ & $\begin{array}{l}\text { Public security } \\
\text { Emergency }\end{array}$ & $\begin{array}{l}\text { Impossibility to secure the towns and difficulty in moving } \\
\text { ambulances, and other emergency vehicles, equipment and } \\
\text { workers. Nearby prison and military premises. }\end{array}$ \\
\hline 5 & Economy & $C_{5}$ & $\begin{array}{l}\text { General economy } \\
\text { Mobile economy }\end{array}$ & $\begin{array}{l}\text { National production may partially decline, citizens who drive } \\
\text { mobile economy may slightly minimize daily rush. Commercial } \\
\text { activities may depreciate and the economy may be weakened. }\end{array}$ \\
\hline
\end{tabular}

3. Linguistic judgment, $r_{i j}$, representing the relative importance of each pair criteria, and

4. Weighting vector, $W_{i}(i=1,2 \ldots n), n=$ number of criteria.

The first step in applying the FAH models is to determine the entire important criteria and their relationship to the decision problem in the form of a hierarchy as shown in Fig. 2. This step is critical because the selected criteria can seriously influence the final choice. The hierarchy is structured from the top levels (the overall goal of the problem: i.e. selection of the most desirable bridge to be maintained first) through intermediate levels (main criteria and subcriteria) to the bottom level (the list of alternatives)

Five linguistic variables are described by fuzzy numbers denoted by Nang [3] as shown in Table 4. Each negative judgment is characterized by its own (conjugate) number to reflect the degree of uncertainty regarding the process, (note: fuzzy numbers for VU versus its negative judgment VI, and LI versus its negative judgment $M I$ ). The $\alpha$-cut concept is applied; in practical application $\alpha=0,0.5$ and 1.0 are used to indicate the decision making condition that has pessimistic, moderate and optimistic view, respectively [6].

Nang's approach employs triangular and trapezoidal fuzzy numbers and the $\alpha$-cut concept to deal with the imprecision inherent to the process of subjective judgment [4], [7] see Fig. 3: triangle LNR and trapezoid LMOR. Note in Fig. 3: The vertical axis represents membership values of element $x$ in the $\alpha$-cut; $L, X_{a M}$ and $R$ being the left, middle and right fuzzy numbers for the triangular $\alpha$-cut, respectively; $L, X_{a L}, X_{a R}$ and $R$ being the two left and two right fuzzy numbers for trapezoidal $\alpha$-cut. 


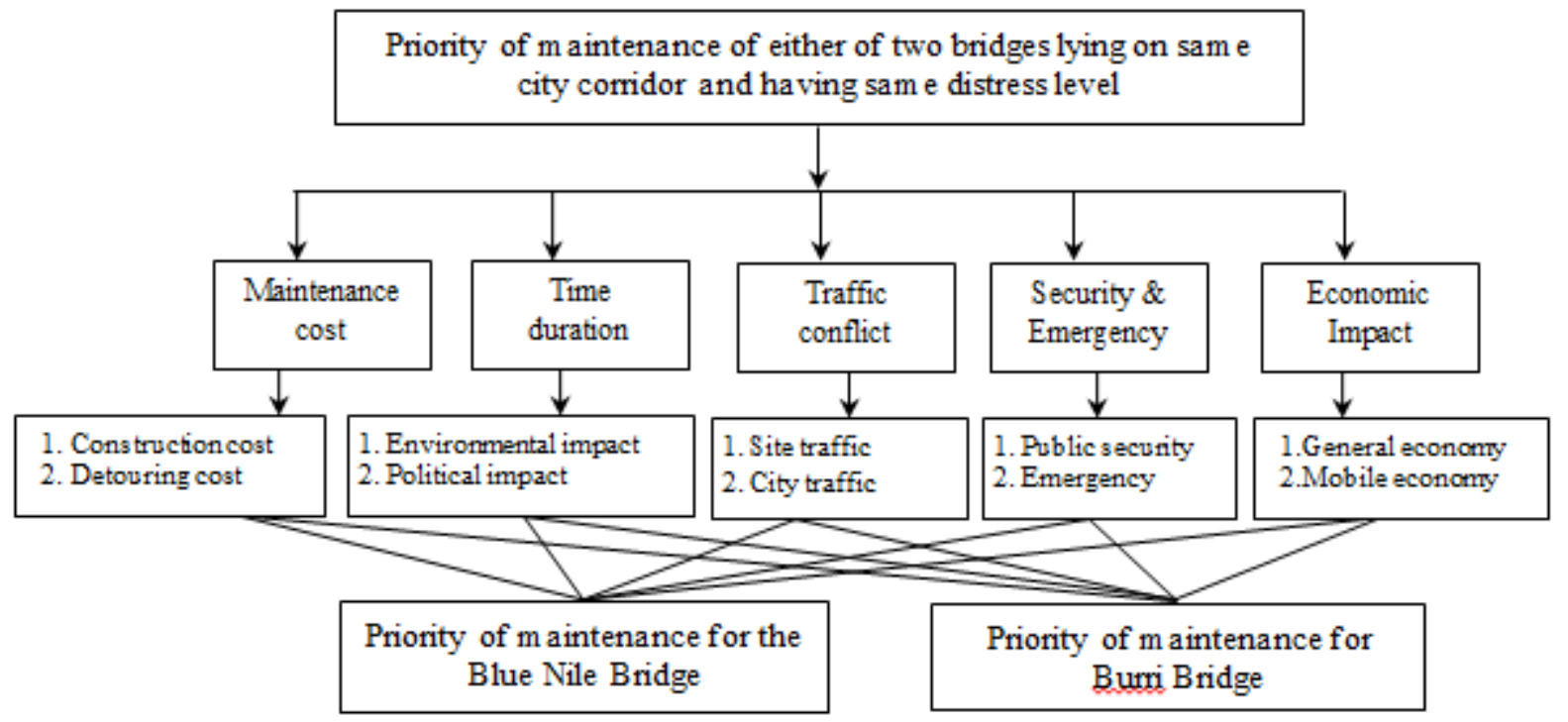

Fig. 2 Hierarchy flow chart

TABLE IV

FUZZY IMPORTANCE SCALE*

\begin{tabular}{ccll}
\hline \hline $\begin{array}{c}\text { Linguistic } \\
\text { judgment }\end{array}$ & Abbreviation & Explanation & Fuzzy number \\
\hline Very & VU & A criterion is strongly inferior to another & $(0,0,1,2)$ \\
Unimportant & LI & A criterion is slightly inferior to another & $(1,2.5,4)$ \\
Less Important & EI & Two criteria contribute equally to the object & $(3,5,7)$ \\
Equally & MI & Judgment slightly favor one criterion over another & $(6,7.5,9)$ \\
Important & VI & Judgment strongly favor one criterion over another & $(8,9,10,10)$ \\
More Important & Very Important & &
\end{tabular}

* Note that the fuzzy numbers for judgments "Very Unimportant" and "Very Important" are represented by half trapezoidal membership functions; whereas the remaining levels are characterized by symmetric triangular membership functions [4].

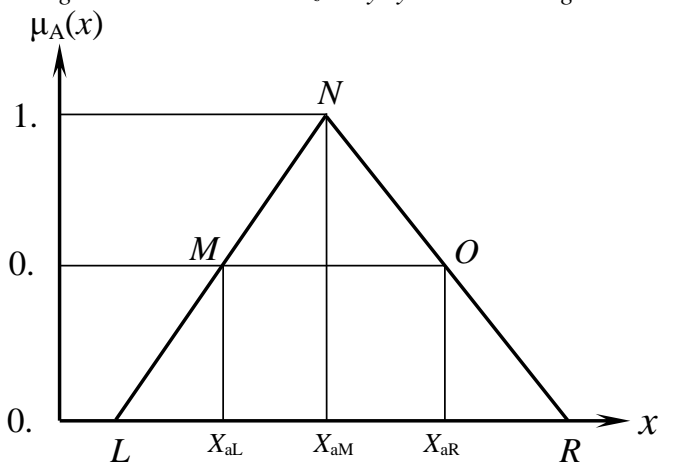

Fig. 3 Triangular and trapezoidal fuzzy intervals under $\alpha-$ cut

\section{B. Case study review}

Both the Blue Nile Bridge and Burri Bridge were recently inspected and evaluated by the MIT. Investigation results indicated that both bridges are in need for urgent repair [1], [2]. The MIT attempted to choose the bridge which is expected to result in less negative impacts when closed partially or completely for maintenance works before the other bridge. The FAHP suggested by Nang [4] is modified and applied here as follows:

The assessment results by the four experts are shown in Reference [10]. i. Four experts (two bridge engineers and two town planners) were asked to identify possible factors that could affect the final decision through several surveys and questionnaires. The criteria used in the hierarchy were obtained and checked through the process using Delphi approach [8], [9].

ii. Five main criteria and ten sub-criteria were adopted for this case study, as shown in Table 3.

iii. Once the hierarchy was established, the opinion of the assigned experts was obtained via questionnaires designed and used for direct pair-wise comparison and judgment.

iv. All possible pair-combinations of experts are examined and analyzed, see Table 5.

TABLE V

PAIR-COMBINATIONS OF THE EXPERTS

\begin{tabular}{cc}
\hline \hline Combination No. & Pair-Combination \\
\hline 1 & Expert 1 with Expert 2 \\
2 & Expert 2 with Expert 3 \\
3 & Expert 1 with Expert 3 \\
4 & Expert 3 with Expert 4 \\
5 & Expert 1 with Expert 4 \\
6 & Expert 2 with Expert 4 \\
\hline \hline
\end{tabular}




\section{Calculation of weights}

The opinion of the four experts is aggregated. Next, the geometric mean of cost $\left(C_{1}\right)$ with regard to duration $\left(C_{2}\right)$, traffic $\left(C_{3}\right)$, security $\left(C_{4}\right)$, and economy $\left(C_{5}\right)$ are calculated as follows:

Applying Equation (7) in reference [3], the fuzzy comparison matrix based on the judgment of expert \#1, regarding the main criterion with respect to the overall goal (using fuzzy numbers in Table 4) will be as follows:

$A_{1}=\left[\begin{array}{ccccc}1 & 3,5,7 & 0,0,1,2 & 0,0,1,2 & 3,5,7 \\ 3,5,7 & 1 & 1,2.5,4 & 0,0,1,2 & 1,2.5,4 \\ 8,9,10,10 & 6,7.5,9 & 1 & 0,0,1,2 & 3,5,7 \\ 8,9,10,10 & 8,9,10,10 & 8,9,10,10 & 1 & 8,9,10,10 \\ 3,5,7 & 6,7.5,9 & 3,5,7 & 0,0,1,2 & 1\end{array}\right]$

Hence, the upper-bound comparison matrix for judgment of expert \#1 will be:

$$
A_{U !}=\left[\begin{array}{ccccc}
1 & 7 & 2 & 2 & 7 \\
7 & 1 & 4 & 2 & 4 \\
10 & 9 & 1 & 2 & 7 \\
10 & 10 & 10 & 1 & 10 \\
7 & 9 & 7 & 2 & 1
\end{array}\right]
$$

The local weight, $W_{i}$, of criterion $i$ is given by:

Where,

$$
W_{i}=g_{i} / \sum_{i=1}^{n} g_{i}
$$

$n=$ total number of criteria,

$g_{i}=$ geometric mean of criterion $i$, given by:

$$
g_{i}=\left(\prod_{j=1}^{n} r_{i j}\right)^{\frac{1}{n}} \quad \therefore g_{l}=(1 \times 7 \times 2 \times 2 \times 7)^{1 / 5}=2.87376
$$

The calculations for $g_{2} \ldots g_{5}$ are similar to $g_{1}$.

Similarly, the geometric mean for $C_{2}, C_{3}, C_{4}$, and $C_{5}$ yields 2.95155, 4.16941, 6.30957, and 3.88234, respectively. Hence, the relative weight of $C_{1}$ can be estimated by using (1) to get: $W_{U 1}=2.87376 /(2.87376+2.95155+4.16941+6.30957+3.88234)=$ 0.14236

Similarly the weights regarding $C_{2}, C_{3}, C_{4}$, and $C_{5}$ can be obtained; the result is shown in the following matrix:

$$
W_{U 1}=\left[\begin{array}{l}
0.14236 \\
0.14621 \\
0.20655 \\
0.31256 \\
0.19232
\end{array}\right]
$$

Thus the weights at different levels: (Low, Medium, Upper) should be calculated for all criteria for the four experts' opinions.

Similarly values of $W_{U 2}, W_{U 3}, W_{U 4}$ and $W_{U 5}$ can be obtained; note that $W_{i}$ is the $i^{\text {th }}$ criterion's weight, where $W_{i}>$ 0 , and $\sum_{i=1}^{n} W_{i}=1$.

For each of the four experts the weight of the selected criterion are applied using (1) and (2) at the three levels of judgment: Lower (L), Medium (M), and upper level (U). Table 6 shows the results of the local weights of Cost. Other criteria are similarly calculated.

Using (3), the aggregate of the two experts' evaluations can be obtained as shown in Fig. 4. Thus, the representative weight of quality $\left(C_{l}=0.3121\right)$ can be found using (4) and Fig. 4, See calculations below:

For the group evaluation, it is required to aggregate manifold evaluators' opinions into one number $(=\mathbf{0 . 1 1 1 7 4}$ for cost, see (8)). The aggregate of multiple experts' evaluations encompasses a range of membership values that must be defuzzified in order to resolve a single representative value.

In Buckley's model [6], [8] fuzzy addition and fuzzy multiplication are used to derive fuzzy weights from group judgment, which are complicated and require considerable

TABLE VI

Assessment Results For THE ALternatives With ResPeCt To THE SUB-CRITERIA

\begin{tabular}{lccccc}
\hline \hline Criterion & Level & Expert \#1 & Expert \#2 & Expert \#3 & Expert \#4 \\
\hline \multirow{3}{*}{ Cost } & $\mathrm{L}$ & 0.11939 & 0.14060 & 0.07897 & 0.12150 \\
& $\mathrm{M}$ & 0.12090 & 0.13351 & 0.09253 & 0.17593 \\
& $\mathrm{U}$ & 0.14236 & 0.16295 & 0.11962 & 0.18950 \\
\hline \multirow{3}{*}{ Duration } & $\mathrm{L}$ & 0.09584 & 0.17249 & 0.18552 & 0.30875 \\
& $\mathrm{M}$ & 0.12641 & 0.18552 & 0.30764 & 0.35820 \\
& $\mathrm{U}$ & 0.14621 & 0.21381 & 0.34581 & 0.39013 \\
Traffic & $\mathrm{L}$ & 0.20346 & 0.16295 & 0.20119 & 0.21911 \\
Impact & $\mathrm{M}$ & 0.20655 & 0.20119 & 0.22297 & 0.22256 \\
& $\mathrm{U}$ & 0.20787 & 0.20718 & 0.23112 & 0.14300 \\
\hline \multirow{3}{*}{ Security } & $\mathrm{L}$ & 0.31256 & 0.27804 & 0.13241 & 0.13715 \\
& $\mathrm{M}$ & 0.36832 & 0.33346 & 0.14698 & 0.14783 \\
& $\mathrm{U}$ & 0.40606 & 0.35029 & 0.35029 & 0.15424 \\
\hline \multirow{2}{*}{ Economy } & $\mathrm{L}$ & 0.17084 & 0.12240 & 0.12240 & 0.09753 \\
& $\mathrm{M}$ & 0.18090 & 0.15336 & 0.19812 & 0.10616 \\
\hline \hline
\end{tabular}

computational time. Instead, the model proposed by Nang employs the fuzzy maximum and minimum operator and center-of-gravity (COG) techniques because of their simplicity [3].

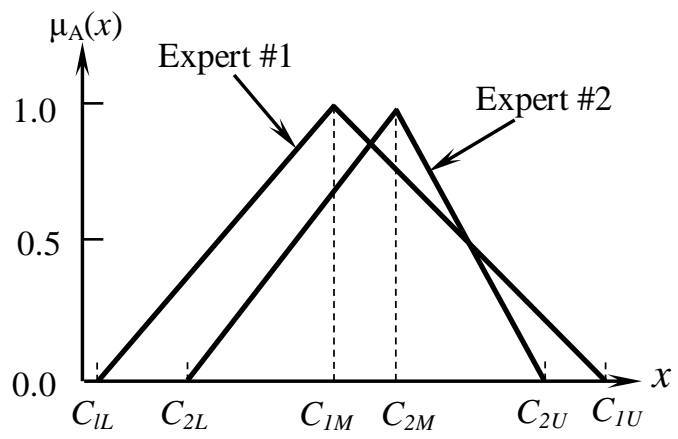

Fig. 4 Aggregation of every two experts' membership

Fuzzy maximum - minimum operator is given by:

$$
\mu_{A}(x)=\max \left\{\min \left[\mu_{1}(x), \mu_{2}(x), \ldots, \mu_{2}(x)\right]\right\}
$$

Where $\mu_{A}(x)$ is the membership value of the element $x$ in the aggregated subset $A ; \mu_{1}(x), \mu_{2}(x), \ldots \mu_{n}(x)$ are membership grades representing the $1^{\text {st }}, 2^{\text {nd }}, \ldots$, and $n^{\text {th }}$ evaluator's judgment, respectively, see Fig. 4.

The COG is given by the following expression:

$$
Z=\frac{\int \mu(z) z d z}{\int \mu(z) d z}
$$


Where $(z)$ is the membership value; $z$ is the weighted average. The overall weight of the $l^{\text {th }}$ sub-criterion, $S_{l}$, are computed as follows:

$$
S_{l}=\sum_{i=1}^{L} W_{k} \times S_{l k}
$$

Where $W_{k}$ is the weight of $k^{\text {th }}$ main criteria and $S_{l k}$ is the local weight of the $l^{\text {th }}$ sub-criterion with respect to the $k^{\text {th }}$ main criteria).

The overall weights of $l^{\text {th }}$ sub-criterion are estimated directly by using experts' judgment of sub-criteria are as follows:

$$
\begin{aligned}
& Z_{\text {cost }}=\left(\int_{0.119391}^{0.12090} \frac{1-0}{0.12090-0.119391}(x-0.119391) x d x+\int_{0.12090}^{0.14236}\left[\frac{0-1}{0.14236-0.12090}(x-0.12090)+1\right] x d x\right. \\
& \left.+\int_{0.1406}^{0.133508} \frac{1-0}{0.133508-0.1406}(x-0.1406) x d x+\int_{0.133508}^{0.16295}\left[\frac{0-1}{0.16295-0.133508}(x-0.133508)+1\right] x d x\right) \\
& \div\left(\int_{0.119391}^{0.12090} \frac{1-0}{0.12090-0.11939}(x-0.11939) d x+\int_{0.12090}^{0.14236}\left[\frac{0-1}{0.14236-0.12090}(x-0.12090)+1\right] d x\right. \\
& \left.+\int_{0.1406}^{0.133508} \frac{1-0}{0.133508-0.1406}(x-0.1406) d x+\int_{0.133508}^{0.16295}\left[\frac{0-1}{0.16295-0.133508}(x-0.133508)+1\right] d x\right) \\
& =0.11174
\end{aligned}
$$

The COG, $Z$, of the opinion weight of every two experts is calculated under the $\alpha$-cut concept according to Nang's enhancement to Buckley model [3], [6] where $\alpha=0,0.5$, and 1 for the different levels of local weights.

By using the foregoing procedures and the four experts' evaluations the weights for cost, duration, traffic, security and economy yielded the values shown in ( Table 7 for Experts 1 and 2), respectively.

The final alternative weights are derived by summing up all the weights; the sum of weights for giving priority of maintenance to the BNB and the sum of weight for priority of maintenance to $\mathrm{BB}$ are shown in the row before last in Table 7 for $\alpha=0,0.5$ and 1.0. Average weights are shown in the last row.

\section{SUMMARY TABLES OF RESULTS}

The following Table 7 shows the reliable result from which the MIT can decide in which bridge maintenance works can be started as alternative with the least negative

TABLE VII

Overall Weights Of THE Alternatives With ResPeCt To JudgMent OF EXPERTS \#1 AND 2

\begin{tabular}{lcccccc}
\hline \multirow{2}{*}{ Criteria } & \multicolumn{3}{c}{ Blue Nile Bridge } & \multicolumn{3}{c}{ Burri Bridge } \\
\cline { 2 - 7 } & $\alpha=0$ & $\alpha=0.5$ & $\alpha=1$ & $\alpha=0$ & $\alpha=0.5$ & $\alpha=1$ \\
\hline Maintenance cost & 0.0600 & 0.0591 & 0.0599 & 0.0329 & 0.0328 & 0.0340 \\
Detouring cost & 0.0220 & 0.0223 & 0.0223 & 0.0223 & 0.0223 & 0.0220 \\
Environmental impact & 0.0320 & 0.0319 & 0.0306 & 0.0222 & 0.0215 & 0.0250 \\
Political impact & 0.0450 & 0.0446 & 0.0446 & 0.0446 & 0.0446 & 0.0450 \\
Site traffic & 0.0620 & 0.0615 & 0.0621 & 0.0376 & 0.0376 & 0.0380 \\
City traffic & 0.0490 & 0.0491 & 0.0492 & 0.0214 & 0.0205 & 0.0220 \\
Public security & 0.1380 & 0.1371 & 0.1389 & 0.0765 & 0.0765 & 0.0770 \\
Emergency services & 0.0620 & 0.0623 & 0.0623 & 0.0623 & 0.0623 & 0.0620 \\
General economy & 0.0340 & 0.0343 & 0.0344 & 0.0186 & 0.0185 & 0.0190 \\
Mobile economy & 0.0590 & 0.0596 & 0.0582 & 0.0493 & 0.0489 & 0.0510 \\
\hline Sum of weights & $\mathbf{0 . 5 6 3 0}$ & $\mathbf{0 . 5 6 1 8}$ & $\mathbf{0 . 5 6 2 5}$ & $\mathbf{0 . 3 8 7 7}$ & $\mathbf{0 . 3 8 5 5}$ & $\mathbf{0 . 3 9 5 0}$ \\
\hline Average weight & & $\mathbf{0 . 5 6 2 4}$ & & & $\mathbf{0 . 3 8 9 4}$ & \\
\hline \hline
\end{tabular}

impacts. When comparing judgments of Expert \#1 with judgments of Expert \#2 the results in Table 7 indicate that starting maintenance of $\mathrm{BB}$ will result in less negative impacts (average weight for $\mathrm{BB}=0.3894$ less than average weight of the $\mathrm{BNB}=0.5624$ )

Similarly, the overall weights of the alternatives with respect to judgment of Experts 2 and 3, Experts 1 and 3, Experts 2 and 3, of Experts 3 and 4, and Experts 1 and 4 are calculated; the results of average weights are given in Table 9. Note that alternative with respect to judgment of Experts 2 and 4 is omitted because it is not expected to change the

decision since 4 out of 5 tested combinations of experts indicated priority of maintenance to BB will result in less negative results regarding the adopted criteria; the best judgments (maximum average weights) are shown bold in Table 8.
Applying the evaluation results of the main criterion with respect to the overall goal and the evaluation results of the sub-criteria with respect to the main criteria for the four Table 7. Consequently, the final alternative weight is derived by summing all the weights. sub-criterion is given by the following equation [3]:

(1)


TABLE VIII

AVERAge WeIght OF PAIR-WISE JUdGMENT OF THE Four EXPERTS

\begin{tabular}{cccccc}
\hline \hline \multirow{2}{*}{$\begin{array}{c}\text { Bridge } \\
\text { Name }\end{array}$} & \multicolumn{4}{c}{ Average alternative weight with respect to each pair of expert judgment } \\
\cline { 2 - 5 } & Experts \#1 and 2 & Experts \#2 and 3 & Experts \#1 and 3 & Experts \#3 and 4 & Experts \#1 and 4 \\
\hline BNB & $\mathbf{0 . 5 6 2 4 0}$ & $\mathbf{0 . 5 6 5 5 0}$ & $\mathbf{0 . 6 1 0 8 7}$ & 0.49906 & $\mathbf{0 . 5 9 3 5 0}$ \\
BB & 0.38940 & 0.42486 & 0.55317 & $\mathbf{0 . 5 2 1 9 2}$ & 0.46840 \\
\hline \hline
\end{tabular}

\section{IMPACT REFLECTION MEASUREMENT}

Throughout Burri bridge maintenance works, which was finished few months ago, the predicted sub-criteria and impacts were actually being evaluated. The most dangerous events and challenging factors affecting the maintenance

TABLE IX

CRITERION IMPACT AND EFFECT

\begin{tabular}{|c|c|c|}
\hline Criterion Impact & $\begin{array}{l}\text { Average weight } \\
\text { of criteria }\end{array}$ & Impact effect \\
\hline Public security & 0.0768 & Expected impacts solved by stopping works many times \\
\hline Emergency & 0.0622 & Expected impacts solved by stopping works many times \\
\hline Mobile Economy & 0.0497 & Not measured \\
\hline Political impact & 0.0448 & $\begin{array}{l}\text { 1. Delayed project, affect quality, stopped major activity not to be applied like the } \\
\text { construction of surface concrete needed to encounter the compression brought by pre- } \\
\text { stressing against the concrete boxes. } \\
\text { 2. Stopped erection of } 4 \text { expansion joints at the ends of main bridge. } \\
\text { 3. Reflected in bad quality of finishing works. }\end{array}$ \\
\hline Site traffic & 0.0378 & Some accidents are reviewed. \\
\hline Maintenance cost & $\mathbf{0 . 0 3 3 2}$ & Affects payments for other ongoing projects. \\
\hline Environmental impact & 0.0229 & $\begin{array}{l}\text { 1. Some claims were registered, e.g. water leaking from } 400 \mathrm{~mm} \text { diameter pipe passing } \\
\text { inside the box girder affected the nearby land users. } \\
\text { 2. Dusts from demolishing old surfacing and transportation. } \\
\text { 3. Claims due to detouring traffic through the local roads and within residential places. }\end{array}$ \\
\hline Detouring cost & 0.0222 & $\begin{array}{l}\text { Addition of } 2 \text { million US Dollars (equivalent to } 25 \% \text { of the estimated maintenance cost) } \\
\text { to solve the detouring axis }\end{array}$ \\
\hline City traffic & 0.0213 & $\begin{array}{l}\text { Changed maintenance policy } 3 \text { times reflected in extending the project maintenance time } \\
\text { to } 30 \text { months instead of } 11 \text { months. }\end{array}$ \\
\hline General Economy & 0.0188 & Not measured \\
\hline
\end{tabular}

\section{DisCUSSION OF RESULTS}

Five models of membership were analyzed to test, in pairs, four experts' judgment on way to achieve refined and reliable result. The total alternative weights with respect to the criteria and sub-criteria reached by the analyses of experts' judgment using FAHP have the follow indications:

1. The total weight of each of the two alternatives with respect to the main criteria and the sub-criteria when analyzing each pair of the experts using alternate modules of all possible pair combinations between the four experts revealed four modeled membership aggregating every two experts agreed to the priority of maintenance to Burri Bridge. Only one model of membership agreed priority of maintenance to Blue Nile Bridge.

2. The results also indicated that the effect of maintenance cost, detouring cost, and mobile economy slightly affected the decision. While public security, site traffic and political impact are the major influencing factors in the decision. The above fact was clearly notices when the outcome from this study is implemented on site.

3. The four Modules in the applied FAHP indicated that starting Burri Bridge maintenance first shall come with least impacts than the other alternative. This fact successfully agrees with the on-going maintenance processes. It is worthwhile mentioning that based on the findings from this research, maintenance of BB is started according to the outcome of this study. Maintenance works and nearby traffic are ongoing smoothly; maintenance works were finished as planned by end of 2015.

4. The results also ascertained that the helping information and data summited to the four experts are enough and useful in achieving best judgments.

5. The results verified that the proposed criteria and subcriteria successfully meet the requirements of the subject 
case study for judgment, note the close weight values obtained.

6. Public security and emergency criteria are believed to have had the most effective impacts with average weights equal 0.0768 and 0.0622 , respectively.

\section{CONCLUSIONS}

The following conclusions are drawn from this study:

1. Political impact, site traffic, and city traffic are the most criteria affecting the decision making in the priority of maintenance of the subject two bridges.

2. Starting maintenance and rehabilitation works of Burri Bridge took the priority of maintenance according to the FAHP analyses conducted on this research. The three utmost affecting criteria are: traffic, emergency and political impacts which are proved to be the most realized criteria from notices on the ongoing maintenance works on BB.

3. Taking opinion of experts in bridge engineering as well as opinion of planners revealed consistent results: as it is noticed that bridge engineers are usually having acknowledged information about other different relevant life aspects, including planning; hence opinion of bridge engineers is found to be in close agreement to planners' opinion.

4. Actions on many technical issues regarding inspection and maintenance of existing bridges and construction of new bridges in Khartoum State were mostly taken through formed technical committees where verbal arguments usually guide to final decisions, i.e. analytical guidance and technical processes are usually absentee. Therefore, a method that shall render many results to be built upon non-linguistics, and the follow-up procedure seems to be difficult.

5. There are many aspects in other public life aspects where the decision making is to be made according to precise investigations and studies, the FAHP when used as guidance to such decisions will result in beneficial outcome. Hence, many of such decisions can be created based on analytical and measureable bases.

6. The public security and emergency are found to have the most effective impacts; while city traffic and general economy have the least impact in the selection of priority of maintenance of the subject two bridges.

\section{REFERENCES}

[1] Ministry of Infrastructures and Transportation. "Evaluation of the Blue Nile Bridge" Report prepared by China JILIN Company \& Beijing University of Civil \& Architecture Engineering, 2009.

[2] Ministry of Infrastructures and Transportation. "Test Repot of Burri Bridge", Report prepared by China Heilong Jiang Roads \& Bridges Construction Company. March 2005.

[3] Nang-Fei Pan. "Fuzzy AHP approach for selecting the suitable bridge construction method". Automation in Construction 17 (2008) 958965.

[4] Ministry of Infrastructures and Transportation. "Sudan Bridges Records", Khartoum State, Sudan, 2013.
[5] Linstone. H. A. Turoff. M., "The Delphi method, techniques and application" Addison-Wesley, London, 1975.

[6] Buckley, J. J, "Fuzzy Hierarchical Analysis", Fuzzy Sets and Systems, 17, 233-247, 1985

[7] Abdelfazl Zarei Babak Maleki.“Using Fuzzy, Delphi Method in AHP to select optimum", Department of Industrial Engineering, Iran University of Science and Technology, 2010.

[8] Hashim M. A. and Onsa, E. H. "Effect of the Construction Method on the Cost and Duration of Bridge Projects in Sudan". Proceedings of the International Conference on Engineering UBI2013 Nov. 2013 University of Beira Interior - Covilhã, Portugal.

[9] Saaty, T. L. "The Analytic Hierarchy Process: Planning, Priority Setting, Resource Allocation" McGraw Hill, NY, 1980.

[10] Salah Eldin Y. Hassan and Eltayeb H. Onsa. "Application of the Fuzzy Analytical Hierarchy Process in the Assessment of Priority of Bridge Maintenance" Proceedings of the $2^{\text {nd }}$ International Conference on Innovations in Engineering and technology (ICCET'2014), Penang, Malaysia, Sept. 2014. 